\title{
Communication for Social Change, Making Theory Count
}

\author{
Pradip Ninan Thomas
}

\begin{abstract}
This article argues for communication for social change theory to be based on a theory of knowledge, a specific understanding of process that feeds into practice, a knowledge of structures, a specific understanding of context and flows of power. It highlights the example of the Right to Information Movement in India as an embodiment of meaningful practice that was in itself a response to the felt needs of people. It argues that the RTI movement provided opportunities to understand Voice as a practice and value through indigenous means, specifically through the mechanism of the Jan Sunwai (Public Hearings). It argues that when local people are involved in articulating 'needs', there will be scope for the sustainability of the practice of communication and social change and opportunities to theorise from such practice.
\end{abstract}

Keywords: communication for social change, voice, right to information, public hearings, political economy, development

\section{Introduction}

Florencia Enghel and Karin Wilkins (2012:9) in their opening piece in the special issue of the Nordicom Review, Communication, Media and Development: Problems and Perspectives, highlight concerns that critical scholars involved in theorising communication for social change have expressed for many years - namely the gaps between resultsoriented, institutionalised approaches and the complexity of context that offers the most fruitful ways to grapple with theory "The strengths of the field lie in those approaches concerned with power, human rights and social justice. Such contributions notwithstanding, in recent years the pressing call for 'demonstrating results' out forward by the development industry' has tended to get in the way of robust theoretical elaboration and independent empirical research. The commissioning of project evaluations more or less overtly called to demonstrate 'success' may be hindering the possibility to learn from contingency and error, and thus to produce critical research that can inform conditions of increased transparency and accountability". While there has been a multiplication of projects, and models across the globe, these developments have rather unfortunately been accompanied by its institutionalisation, its corporatisation and enclosures. There occasionally are strong critiques of our field like the writings of Mohan Dutta (2011) who also offers frameworks grounded in culture for understanding health communication and communication resistance in the context of our resolutely neo-liberal times although 
we tend to rely in our pedagogy on texts that were written for another era. This then is one aspect of the equation - theorising that seems to have lost its way in the context of the fetishism of practice.

Another more or less insidious reality is the growing corporatisation of the enterprise of communication for social change. When large institutions such as the CSC Foundation encourage enclosures by trademarking the very term 'Communications for Social Change' (for the second year running and in the context of the annual CSC Awards - I received an email on the $3^{\text {rd }}$ of January, 2012 reminding us that this was a trademarked term), I think that there is something deeply wrong with this field. Should theory address such concerns, should theorists engage with such concerns or should we like the proverbial ostrich, bury our heads in the sand and hope that the problems will disappear as we lose ourselves in the practice of CSC? What kind of a practice should theory be an aid for? And is the time right for us to really understand 'social change' as opposed to 'communication'? Let me quote a passage from Vincent Mosco (1996: 71-72). In his classic text The Political Economy of Communication, he describes the basis for a critical political economy of the media "Decentring the media means viewing systems of communication as integral to fundamental economic, political, social and cultural processes in society....the point is that the political economy approach to communication places the subject within a wider social totality.....Both political economy and communication are mutually constituted out of social and cultural practices. Both refer to processes of exchange which differ but which are also multiply determined by shared social and cultural practices". Decentring however does not mean marginalising the analysis of the media. Rather, the media and political-economy need to be seen as 'mutually constitutive', distinct but also co-terminous, synergistically related and as two sides of the same coin. Is it time to do this with CSC theory - decentre our main concerns with some of our key words such as participation etc. and really understand what is required to make practice work?

The theorisation of CSC has always been dependent on borrowings from other disciples - from rural sociology that provided the basis for the diffusion model to the radical pedagogy best illustrated by the contributions made by the Brazilian educator, Paulo Freire. Freire's theory is a classic example of critical social science given that it was built on a theory of false consciousness, a theory of crisis, a theory of education and a theory of transformative action (See Fay: 2011). While 'false consciousness' sounds like a quaint Marxian category from yesteryear, in my way of thinking it is important that we invest in understanding how power flows and affects understandings and shapes mindsets related to the practice of CSC. CSC theorisation has also been shaped by a great variety of 'isms' and schools of thought including Marxism, feminist theory, post-colonial and subaltern theories, identity theory, globalisation, social movement theory and ICT for development theories. In recent times, social networking and urban interventions have also contributed to shaping the practice of CSC, although this is yet to be reflected in its theory. While one can argue that these many borrowings and traditions of inter-disciplinarity have contributed to the shaping of CSC as a field and to its dynamism, it is also clear that a consequence of these many influences is the existence of a variety of fault lines - between theory and practice, between technology and the 
social, policy and the implementation of policy, the global and the local, technocratic and managerial approaches versus endogenous, people-centred approaches. While fault lines in themselves are to be expected, can be healthy, and are a reflection of conflict and contestations, many have argued that there has been a grand co-option of all those terms that once seemed to suggest that another world is possible. The terms that are a key part of the identity of CSC have themselves been shorn of their original meaning.

The Slovenian philosopher Slavok Žižek, who has been described as an 'all-purpose' subversive, has pointed out the limits of corporitised 'causumerism' and the slackvitism that accompanies corporatized approaches to social change. This is the Bono version of social change where corporations fulfil their social responsibilities by dealing with issues such as poverty through the act of consumption. American Express contributes to fighting AIDS through funnelling a percentage of its profits to the Red project that facilitates the purchase and distribution of anti-retroviral drugs in Africa although we are not sure of how much is actually sent to Africa. Žižek uses the example of those with a heart buying into the goodness encapsulated into a cup of coffee bought from Starbucks. He argues that as 'caring capitalists' we buy the coffee because of the promise that the coffee is bought via a corporate strategy that embraces Fair Trade and in which part of the profits go to help starving children in Uganda. As he points out "The "cultural" surplus is ... spelled out: the price is higher than elsewhere since what you are really buying is the "coffee ethic" which includes care for the environment, social responsibility towards the producers, plus a place where you yourself can participate in communal life..." (53-54). The upshot of our involvement in such circuits of cultural consumption is that we end up contributing to initiatives that are destined to forever deal with the symptoms of poverty but never with its causes that include unjust trade practices, poverty and exploitation, the issue of land, etc. Participation in this utopia is limited precisely because it does not give either the producer or consumer the opportunity to take part in an exercise of freedom. It is very similar to the 'slacktivist' cultures that are rife in the era of social networking. This is a culture that encourages people to click and contribute to online polls and issues but that does not enable an engagement with real issues in the world of the here and now. NGOs, for the most part, tend to replicate the logic of neo-liberalism and participation therefore tends to become the means for extending the project of neo-liberalism through enabling people to participate in a variety of forms of 'compassionate capitalism'. Žižek points out that while we might feel good consuming that cup of coffee and knowing that part of the profits is being used to fund an operation to set right a child with a cleft palate - we only end up massaging the symptoms but not the real causes of poverty including unequal trade, global pricing of primary commodities, corruption and poor governance. In other words, transformative change is almost always impossible. We always end up shuffling the chairs although we also hope that shuffling it in the right order might make a difference. Does CSC theory end up massaging the symptoms when we ignore dealing with causes? When we do invoke our favourite key words - participation, development, empowerment, are we merely invoking empty signifiers?

In spite of the evidence of quantum, what seems to be the case is that the 'practical horse' has bolted leaving the 'theoretical cart' behind. In other words the literally thousands 
of CSC initiatives are yet to become foundational material for an explication of theory reflective of and that is conversant with the local. I used to work for the international ecumenical NGO, the then London, but now Toronto-based World Association for Christian Communication (WACC) in the good old days when money was not an issue as it is today. In the 15 years that I spent at WACC, we must have supported more than a 1000 CSC projects, although with one or two exceptions there was little sustained reflection on the learnings from projects. I suspect that this lacunae is largely the reasons for the accent on matrix based evaluations and impact studies that are a mandatory aspect of project support today. The accent in other words, is now on evaluation. The advent of the 'participatory' model has further stymied theoretical innovation given that this was interpreted as the 'Holy Grail' that would usher in the promised land characterised by communications for all. Today key words such as development, participation, social capital, poverty reduction, civil society and empowerment, among others have an auratic power that disallows any form of questioning. Issue 4-5 of the journal Development in Practice, 17, 2007 is devoted to a deconstruction of such key words and Andrea Cornwall (2007:471) in an article entitled Buzzwords and Fuzzwords: Deconstructing Development Discourse, makes the following observation “ Development's buzzwords are not only passwords to funding and influence... The word development itself ....has become a 'modern shibboleth, an unavoidable password', which comes to be used ' to convey the idea that tomorrow things will be better, or that more is necessarily better'... the very taken-for-granted quality of 'development'... leaves much of what is actually done in its name unquestioned". And yet, for most of us involved in theorising CSC, these key words are often uncritically invoked and used.

One can argue that communications and development theory consists in the main of principles that become the basis for pathways to practice. Any theory is based on five distinct levels - 1) A theory of knowledge - in other words an epistemological understanding of why and how a communications intervention will result in the required change. In other words principles, concepts, assumptions that are part of a coherent framework. So in the case of edutainment, this epistemology is based largely on Albert Bandura's concept of para-social identifications or audience identification with a role model as the basis for behavioural change. A theory of knowledge in the context of communication and development will need to be explicit about how theory can be translated into practice. Paulo Freire for example had a very clear theory of knowledge that is highlighted in this short excerpt. 2) A specific understanding of process that feeds into practice - based on an epistemology of process. In the community radio movement for example, there is a specific belief in the validity of community-based participation in the operationalisation of community radio. These practices vary from station to station but this is what distinguishes this mode of radio from others. Today, a whole raft of participatory communications practices - from participatory rural appraisal to participatory planning and evaluation and action research related processes have now become mainstreamed. 3) A knowledge of structures, meaning the institutions and power flows that play a role in the structuring of processes, interventions and access to resources. This is a problematic area in theory as CSC theory often skirts this issue and presents theory purely in the realm of ideas, principles and propositions. Take for example ICT4D theory. Much of is based on Information Systems theories - theories that in the main deals with the 
ways in which hardware, software, data, people and process interfaces can contribute to the generation of reliable information. This is welded to some version or other of Modernisation theory. All too often IS theory is the mould for ICT4D theorising and there is a tendency to drape this mould with the social. So one issue that is of central concern today is what should come first in the context of theory building in the CSC - the social or the technological? 4) A specific understanding of context-meaning the environment and community that is the location for the intervention. Any intervention has to be conversant with its locality in all its complexity - tradition, hierarchy, culture, norms, divisions, power flows, politics. And 5) A grappling with the flows of power. In other words, the accent on power recognises the fact that no CSC project exists in a vacuum or is outside of the influence of a variety of stake holders - from its funders, to the local implementers to the actual beneficiaries Theory, in other words, needs to have sufficient explanatory power and offer pathways to understanding context.

When these five levels are applied to an assessment of CSC theory, it is clear that in most cases one or the other level is often privileged at the expense of other levels, resulting in an incomplete theory. For example if one were to use these levels to explore ICTs for development theory projects in India, it will become clear that the level that dominates is that of practice. This is to be expected given that there is a belief that telecentre projects for example, will result in 'push' and 'pull' effects and eventually to information flows that make a difference in the lives of people. E-governance, for example, is based on the 'pull' factor - meaning people accessing and making use of online information related to a variety of services. In other words the theory of knowledge associated with ICTs is more often than not 'taken for granted' rather than based on a clear and sophisticated understanding of the relationships between technologies, peoples and structures. Often a knowledge of structures is not factored in and neither is a knowledge of context. There are exceptions such as the Bhoomi (Land) project in Karnataka, India, that was specifically directed towards creating an accessible database of land records that could be accessed by the local farmer without having to enlist the help of the local revenue officer. In the case of Bhoomi, the computerisation of land records and the provision of district-wide kiosks based on biometric identifications helped 'disintermediate' - i.e. cut out the middle man resulting in efficient, access to land records.

\section{Validating People's Resources: Theorising 'Voice' in the context of the RTI Movement in India}

One of the most fascinating examples of a grounded theorising in CSC stems from the RTI movement in India. While the articulations of this theory has been in bits and pieces, it is clear that taken as a whole, it consists of a theory of knowledge, of processes and practice, structures and context that is as grounded as it can get. Specifically this theory articulates a pathway to understanding the role of ordinary people in demanding accountability and transparency through social action. One can argue that the Right to Information campaign in particular has helped many people to experience the real value of participation, access and empowerment in their lives. One of the strengths of these projects is that they have been based on 'listening' to, taking account of and responding to people's needs - a basic tenet in communication and social change that has often 
been neglected or at best half-heartedly embraced. The art of listening is of course the central theme in Wendy Quarry and Ricardo Ramiriez's (2009) book Communication for another Development: Listening Before Telling. Listening to the voices of people helped validate the RTI's program commitment to transparency and accountability that eventually became a nationwide movement and the basis for an epochal legislation. Secondly the valorisation of 'voice.' Here of course Nic Couldry, Jo Tacchi and others have made a strong case for the inclusion of Voice. Theorisations of Voice do have the potential to contribute to a deepening of understandings of participatory communications. Couldry's book Why Voice Matters explores Voice in the context of neo-liberalism's undervaluation of Voice, the drowning out of Voice by the power and force of the Market and the resulting inability of people to 'give an account of themselves'. He argues that Voice needs to be seen as an essential aspect of the Social, as the enacting of reflexive agency and an embodied process. Voice however, is routinely undermined by neo-liberal, voicedenying rationalities.

Voice needs to be seen not simply in terms of the human capacity to create sounds but the right to speak in contexts in which that right is a privilege associated with the structures of domination undergirded by caste, class and gender. Taken in this sense, the spoken voice in the context of public hearings popularised by the RTI movement in India is an invitation to listen and dialogue. The empowerment that results from 'naming' corruption and non-accountability is an act of freedom precisely because that act connects self, and the obligations of self to the community thus strengthening the larger environment of a communicating public (see Thomas, 2011). The Jan Sunwail (public hearing) is an important indigenous means and pedagogical device used by this movement to mobilise, radicalise and give voice to marginalised people who have traditionally been expected to remain silent, even in the face of the most atrocious atrocities committed by the upper castes and wealthy individuals. As Jenkins describes it:

A jan sunwai is a publically accessible forum, often held in a large open-sided tent pitched on a highly visible spot, at which government records are presented alongside testimony by local people with first hand knowledge of the development projects that these records propose to document. Key pieces of information from project documents are read aloud. Those with direct knowledge of the specific government projects under investigation are invited to testify on any apparent discrepancies between the official record and their own experiences as labourers on public-works projects or applicants for means-tested antipoverty schemes (Jenkins, 2007:60). Most importantly the Jan Sunwai is a mechanism that affirms Voice, strengthens self-confidence often in contexts where caste and class collude to silence people. In the context of the RTI movement, these public hearings allowed local people to examine both the information and dis-information on local development, the collusions, the silences, the corruption and the political economy of under-development. In the words of the Dalit intellectual Gopal Guru "The sunwai is a public hearing but it is different from legal and procedural hearings instituted by the state which by its official, legal, and almost pompous nature, place the victim at an inherent disadvantage. The sunwai restores to a person his place in the system by allowing him to represent himself and make himself heard". 
In other words the theorising of Voice as both a right and as a process is grounded in the local - a way in which memory, experiences, local knowledge were mobilised to effect processes that has clearly resulted in transformative change. The national impact of this movement has been varied. However, it has clearly demonstrated how theory and practice can be closely linked and in my way of thinking offers what the theorising of CSC can be based on. What makes the theorising of the RTI really interesting is that it is not based on a discrete theorising of information, but of how access to information as an enabling right can become the basis for other rights including food security and the right to employment.

The experience of the RTI clearly indicates that communication and development projects work best when local people articulate their own needs. In the case of the RTI, accountability and transparency struck an immediate chord and that led to a national movement. Local resources and practices such as the Jan Sunwai were used to mobilise communities and it resulted in individuals understanding exactly how access to information can be leveraged into a movement for social change. If we are to assess the impetus for communication and development projects in India and local buy in, it will become clear that the impetus for the vast majority of projects stems from outside the community. While external interventions are fundamentally important given that the flow of ideas and innovations related to immunisation, safe sex practices, agricultural growth, new social practices are necessary, it is not always the case that such interventions are preceded by proper, extensive consultations with the community. In other words, the articulation of needs remains to a large extent the privilege of external agents rather than local people. The theorising of Voice and a graded understanding of the cultural and social basis for Voice, the ways it is cultivated in local contexts along with the mechanisms for Voice, slogans, public hearings, posters, political songs, puppet shows, etc. need to become a part of this theorising project. While such devices and mechanisms were factored into development in the past, it was more often than not agency-led rather than people-led. Today, the national spread of key words such as transparency and accountability provides another opportunity to theorise a communications for development for our times that is grounded in an understanding of needs, structures and processes.

\section{Conclusion}

Theorising in communications and development needs to keep up with changing contexts, technologies, trends and understandings. For theorising to be relevant, its frameworks need to respond to the five factors mentioned in this chapter: epistemology, structures, practices, context and power. The context of communication and development in India is very different from what it was thirty years ago. The mood of the people too has changed and it would also seem that the 'ambivalent' State is also open to listening to and responding to the voices of both people and civil society. The Right to Information movement is an example of what seems to be a new contract between the State and citizens. The example of the right to information movement in India and in particular the relationship between public hearings and 'voice' does suggest that CSC theory can be reinvigorated and revitalised through the exploration of interventions and innovations that are culturally relevant and local. The theorisation of Voice does contribute to 
understandings of 'participation' and social change. Most importantly, the example of the right to information movement does suggest that when local people are involved in articulating 'needs', there will be scope for the sustainability of the practice of communication and social change and opportunities to theorise from practice. While many imponderables are bound to remain, theorising simply has to keep up with the times, and respond to and account for local needs and categories in order to remain relevant.

\section{References}

Couldry, N. (2010). Making Voice Matter. London, Sage.

Cornwall, A. (2007). Buzzwords and fuzzwords: Deconstructing development discourse (471-484), Development in Practice, 17, 4-5.

Dutta, J. M. (2011). Communication Social Change: Structure, Culture and Agency, NY \& London, Routledge. Enghel, F. \& Wilkins, F. (2012). Mobilizing Communication Globally: For what and for whom? (9-14), Nordicom Review 33, Special Issue.

Fay, B. (2011). Critical Social Science, Critical Quest, New Delhi.

Guru, G 'Jan Sunwai: A New Instrument of Democracy in India', Democracy Asia, http://www.democracyasia.org/casestudies_studies_gopal_guru.htm <February 11, 2008>

Jenkins, R. (2007). Civil society versus corruption (55-68), Journal of Democracy, 18, 2

Lokniti Newsletter, 8, November 2005.

Mosco, V. (1996). The Political Economy of Communication. Sage Publications.

Quarry, W. \& Ramirez, R. ( 2010) Communication for Another Development. Listening Before Telling. London, ZED Books.

Thomas, P. N. (2011). Negotiating Communication Rights: Case Studies from India, New Delhi, Sage.

Žižek, S. (2009). First as Tragedy, Then as Farce. London/NY, Verso. 